\title{
Depois do fim do platonismo fenomenológico \\ Hermann Lübbe e a descrição da aceleração civilizacional moderna
}

After the end of the phenomenological Platonism

Hermann Lübbe and the description of the modern civilizational acceleration

Sérgio da Mata*

Hermann Lübbe zum 90. Geburtstag

Resumo: O objetivo do artigo é oferecer uma visão geral da obra filosófica de Hermann Lübbe. Para tanto, deu-se ênfase a dois de seus principais campos de investigação: história da filosofia e fenomenologia da experiência do tempo nas sociedades modernas. A exposição está organizada em quatro momentos: (1) contextualização intelectual, (2) as críticas de Habermas às suas posições, (3) o pluralismo metodológico de Lübbe e (4) sua descrição das consequências sociais e culturais da aceleração civilizacional moderna, bem como as possibilidades que se abrem para tal abordagem na análise das "jornadas de junho" de 2013.

Palavras-chave: Hermann Lübbe. Fenomenologia. Aceleração civilizacional.

Abstract: The purpose of this article is to offer a first overview of Hermann Lübbe's extensive philosophical work. Two of his main research topics are stressed here: the history of philosophy, and the phenomenology of time experience in modern societies. This has been done through the following steps: (1) intellectual contextualization, (2) Habermas' criticisms on his positions, (3) Lübbe's methodological pluralism, and (4) his description of the social and cultural consequences of modern civilizational acceleration, as well as some possibilities for this approach in the interpretation of the Brazilian protest waves of June 2013.

Keywords: Hermann Lübbe. Phenomenology. Civilizational acceleration.

* Doutor em História pela Universität zu Köln (Köln, Alemanha), professor do departamento de História da Universidade Federal de Ouro Preto (Ufop), em Ouro Preto, MG, Brasil <sdmata@ichs.ufop.br>.

Civitas, Porto Alegre, v. 17, n. 3, p. 523-541, set.-dez. 2017 
Muitos filósofos se dizem amigos da história, mas poucos são amigos dos historiadores. Hermann Lübbe pertence a este segundo e reduzido grupo, o dos filósofos que acreditam que os historiadores também têm algo, às vezes algo realmente importante, a dizer. E embora tenha declarado em entrevista ser "apenas um leitor diligente e também um admirador dos trabalhos de nossos historiadores" (Lübbe, 2010, p. 37), é fato que de sua extensíssima produção destacam-se importantes estudos de história conceitual, de história das ideias filosóficas, da ciência e das instituições universitárias (Lübbe, 1992; Lübbe 1993). Misto de filósofo, historiador e cientista social, em seus escritos jamais se encontra aquele "desprezo pelo cotidiano" que a seu ver caracterizaria a tradição filosófica alemã (Lübbe, 2010, p.46-47). Bem poderia ser esta uma das explicações para o fato de que, diferentemente de outros representantes da "geração cética" (Schelsky, 1957), se manifesta no caso de Lübbe uma enorme distância entre sua efetiva importância no debate filosófico e intelectual interno e o virtual desconhecimento que vigora a seu respeito no mercado global das ideias.

Como estudante de filosofia e jovem professor assistente, Lübbe percorreu e conheceu de perto as principais correntes filosóficas da Alemanha do pós-guerra. Em sua juventude ele foi fortemente influenciado por dois de seus professores em Münster: Heinrich Scholz e Joachim Ritter. Em Freiburg, assistiu aos cursos de Max Müller, Heidegger e Wilhelm Szilasi - com quem se doutorou. Foi assistente de Ludwig Landgrebe em Colônia e de Gerhard Krüger em Frankfurt am Main. Frequentemente viajou a Lübeck para participar do círculo de Wilhelm Schapp.

Dessa constelação destacam-se os nomes de Ritter, Schapp e Landgrebe. Os interesses do primeiro se orientavam para a análise dos processos que liberaram a subjetividade na história, o indivíduo e seus direitos, sua esfera privada e interioridade (Lübbe, 1978), definindo assim um campo de problemas com os quais trabalhos de Lübbe se relacionam intimamente. Quanto à ascendência de Schapp e Landgrebe (o segundo orientando e o último assistente de Husserl, respectivamente), ela se situa num outro plano, o do método. Embora Lübbe tenha se notabilizado como um pensador do político, interessa-nos sublinhar aqui a sua singular articulação entre fenomenologia e ciências da realidade. A partir do "ataque ao objeto universal" movido por Schapp (2007, p. 81) na década de 1950, e que Lübbe de imediato afirmou ter demarcado o "fim do platonismo fenomenológico" (Lübbe, 1954, p. 650), a filosofia pôde abrir seus olhos não apenas para o mundo da vida, mas também 
e sobretudo para a importância das ciências da realidade. Mais histórica que eidética, a fenomenologia de Lübbe procura se situar em algum ponto intermediário entre filosofia e ciências sociais. Ela não se confunde porém com uma proto-sociologia, à medida em que busca oferecer uma descrição densa, empírica, da dinâmica cultural moderna. ${ }^{1}$ Alheia tanto aos grand récits quanto à tentação de se hipostasiar a teoria, sua obra traduz um contínuo esforço de recuperação da racionalidade intrínseca ao senso comum, esforço que Lübbe geralmente justifica com a seguinte frase: "o trivial é o fundamental".

\section{2}

É sabido que a filosofia exerceu um papel central na Alemanha do pósguerra não tanto como disciplina acadêmica, mas sobretudo como instância privilegiada de orientação. A partir do embate público entre os representantes da teoria crítica e o grupo em torno de Joachim Ritter (Schweda, 2015), e que se estendeu ao longo das décadas de 1960-1980, convencionou-se chamar aos últimos "neoconservadores".

Naqueles anos, entre as jovens promessas da filosofia acadêmica alemã, a importância de Lübbe só pode ser comparada à de Habermas. Entre 1966 e 1973, ele exerceu o cargo de secretário de educação superior do governo social-democrata da Renânia do Norte-Westfália, tendo mais tarde ocupado o posto de assessor do governo democrata-cristão de Baden-Württemberg. Especula-se que sua influência se fez sentir até mesmo em discursos do então chanceler Helmut Kohl.

Para alguém que desempenhou um importante papel na história da edição crítica das obras de Max Weber e que toma assento no comitê editorial das obras completas de Marx e Engels, a designação de conservador ou neoconservador certamente tem algo de caricatural. Como quer que seja, ambos os termos foram reiteradas vezes empregados para se referir a Lübbe. Há mesmo quem veja nele "o mais importante porta-voz do neoconservadorismo" (Lorig, 1988, p. 80). Ontem, como hoje, os intelectuais que não se identificavam com um certo radicalismo de esquerda dificilmente poderiam aspirar àquilo que Weber chamava de a duvidosa coroa da popularidade. Lübbe jamais se esquivou do debate com seus adversários, e referiu-se ironicamente à teoria crítica como um "marxismo tardio" (Kohler e Kleger, 1990, p. 13). Tendo percebido que em circunstâncias assim é inútil produzir desmentidos, achou que seria o caso de dar o termo "conservador" um sentido mais preciso. Para Lübbe o

\footnotetext{
${ }^{1}$ Para o cientista político Reinhard Mehring (2009, p. 63), "como nenhum outro, Lübbe é capaz de tornar visíveis e empiricizar teoremas histórico-filosóficos por meio de exemplos".
} 
conservadorismo não é nem pode ser um fenômeno marginal nas sociedades modernas, uma vez que elas estão marcadas simultaneamente por uma acelerada transformação e por um "conservadorismo estrutural" (Lübbe, 1997, p. 328-338). Se ser um (neo)conservador significa admitir a inevitabilidade deste equilíbrio e, ao mesmo tempo, manter-se fiel ao imperativo da argumentação racional, Lübbe diz não ter qualquer problema com o termo. De fato, uma análise sóbria das estruturas do nosso mundo tende a confirmar sua tese de que "diminui cada vez mais a cota daquelas reformas que celebram a si mesmas como concretizações das assim chamadas utopias concretas". Em última análise, conclui, "conservadora, cultural e ecologicamente, institucional e moralmente, é a predisposição para uma relação cuidadosa com recursos que diminuem de forma não restituível" (Lübbe, 1981, p. 65-66).

Mas estaríamos abusando do critério da seletividade caso passássemos ao largo do que dizem os seus críticos. Por questão de comodidade, nos limitaremos aqui ao mais conhecido deles. Como Jürgen Habermas caracteriza o neoconservadorismo? Ele acredita que esta corrente de pensamento se coloca numa linha de descendência direta em relação aos pensadores da "revolução conservadora" da República de Weimar, figuras como Ernst Jünger, Carl Schmitt e Hans Freyer. Depois da guerra, uma geração intermediária (Ernst Forsthoff, Arnold Gehlen e Joachim Ritter) teria admitido a possibilidade de progresso da civilização, mas permanecido firme em sua crítica da cultura, na mesma atitude de melancólica recusa da modernidade. O esforço desta geração intermediária, levado a cabo na década de 1950, consistiria em articular a aceitação da "modernidade social" com a rejeição da "modernidade cultural". O conservadorismo seria o tenor comum à interpretação "fascinante" (o termo é de Habermas) que Ritter fez de Hegel; à apropriação de Schmitt por Forsthoff; à teoria das instituições e a crítica dos intelectuais em Gehlen e Schelsky. A ligação de Lübbe com o pensamento de Ritter e seus contatos eventuais com Schmitt fariam dele, sugere Habermas, uma espécie de atualizador da "revolução conservadora".

Na década de 1970 surgiria outro pomo de discórdia entre os novos hegelianos de "esquerda" e os de "direita": as disputas em torno das reformas educacionais que se pretendia implementar na República Federal da Alemanha. Para Habermas elas eram necessárias em vista das "mudanças socioestruturais" em curso, da burocratização e cientificização do sistema de ensino. Os conservadores teriam se aproveitado da ocasião para caracterizar as reformas como "revolução", valendo-se da pouca simpatia que elas suscitavam na população e, assim, mobilizar o "ressentimento de classe média" contra 
a esquerda, sugerindo a existência de uma ligação entre crítica social, reforma educacional e terrorismo político. ${ }^{2}$ Desacreditados do progresso, os neoconservadores manteriam fortes elos com a tradição historicista: daí a sua revalorização da narrativa, a desconfiança em relação à história "como ciência social" da Escola de Bielefeld e uma suposta "desvalorização da sociologia e das ciências sociais em geral". Através de uma leitura no mínimo singular das teses de Gehlen sobre a arte moderna e a Posthistorie, Habermas afirma existir uma estreita ligação entre neoconservadorismo e pós-modernismo. ${ }^{3} \mathrm{O}$ neoconservadorismo enfatizava a "coragem de educar" e a "coragem para com o passado". ${ }^{4}$ Seus representantes pretenderiam mobilizar pedagogicamente determinados passados em detrimento de outros (Habermas, 1989, p. 32-44).

Para Habermas o perigo deste "retorno" ao historicismo ("neohistoricismo") da década de 1970 estava em sua suposta reação à aplicação de métodos das ciências sociais à história, isto é, estaria num injustificável retorno à tradição da historiografia oitocentista. O mote principal do neo-historicismo, sentencia Habermas: a reabilitação da narrativa. Ainda mais graves seriam suas consequências políticas, advindas da historicização do holocausto. A real fundação da República Federal da Alemanha teria ocorrido por obra das novas gerações, sob o peso da catástrofe moral de Auschwitz, razão pela qual insistir numa tal historicização significaria colocar abaixo não propriamente um tabu, mas o eixo em torno do qual a identidade da segunda democracia alemã teria se constituído (Habermas, 1990, p. 149-156). As mesmas críticas, apenas menos sutis, seriam feitas por outros autores filiados à teoria crítica, como Herbert Schnädelbach, Karl-Otto Apel e Ernst Tugendhat (que cunhou a expressão "anti-iluminismo" para se referir aos neoconservadores). ${ }^{5}$

${ }^{2}$ O pano-de-fundo é a realização, em 27 de novembro de 1974, do chamado TendenzwendeKongress na Academia de Belas Artes da Baviera, e em que tomaram parte Lübbe, Robert Spaemann, Ralf Dahrhendorf e Golo Mann, entre outros.

${ }^{3}$ Isso não vale em absoluto para Marquard, Lübbe e Spaemann. Andreas Huyssen fez uma boa análise das contradições de Habermas a este respeito (Huyssen, 2006, p. 342-355).

${ }^{4}$ Mut zur Erziehung foi o tema de um congresso entre 9 e 10.01.1978, ao final do qual Wilhem Hahn, Nicolaus Lobkowicz, Hans Bausch, Golo Mann, Lübbe e Spaemann publicaram nove teses que, dado o clima de polarização à época, geraram grande polêmica. Tugendhat e Habermas criticaram duramente o documento. As teses em questão rejeitavam a difusão de uma "ideologia emancipatória" por meio do sistema de ensino, ao invés da ênfase em virtudes como o bem, dedicação, disciplina e ordem; rejeitavam ainda o elogio da igualdade em prejuízo da competência etc. Segundo Hacke o espectro das opiniões entre os autores do documento era amplo, e tanto Spaemann quanto Tenbruck se manifestaram em prol de um ideal de formação humanista (Hacke, 2006b, p. 110-111). Já para os frankfurtianos, Lübbe, Spaemann e Friedrich Tenbruck seriam a expressão intelectual mais sofisticada da "direita".

${ }^{5}$ Assim como Tugendhat (1997, p.214-223), Apel (1999, p. 194 e 199) dirigiu suas baterias contra a "crítica neoconservadora-pragmática da utopia" que ele identificava em Gehlen, Schelsky e Lübbe, entre outros. Apel dedicou especial atenção às posições de Lübbe, por se tratar de um "crítico da ética discursiva utópica". 
Sendo um pensador liberal, Lübbe nunca deixou de explicitar a distância que o separa das posições políticas de intelectuais como Carl Schmitt, Ernst Jünger e outros representantes do pensamento autoritário da República de Weimar. ${ }^{6}$ Sem entrar na minúcia de seus argumentos, façamos agora um esforço de epoché político-ideológica, de modo a avaliar sine ira et studio alguns aspectos da sua contribuição ao conhecimento histórico-social da modernidade.

Que há de tão interessante assim neste que é um dos mais renomados alunos de Ritter? A nosso ver, o fato de que seu estilo de pensamento traduz à perfeição o caráter pluralista e antidogmático que caracterizava este círculo, bem como o lugar central que a sociologia e o pensamento histórico ali assumiram. Ritter tinha sido orientando e assistente de Ernst Cassirer, acompanhado-o, inclusive, por ocasião do famoso debate com Heidegger em Davos. Depois de assumir sua cátedra em uma Münster ainda em ruínas, ele teve a felicidade de reunir em torno de si algumas das mais talentosas cabeças da nova geração. Em seu collegium philosophicum tomavam parte jovens promissores como Karlfried Gründer, Ernst-Wolfgang Böckenförde, Martin Kriele, Robert Spaemann, Gunter Scholtz, Rudolf Vierhaus, Odo Marquard e Hermann Lübbe. Spaemann (2010, p. 112) descreve este grupo como um misto de "tomistas, teólogos protestantes, positivistas, especialistas em lógica, marxistas e céticos". Lia-se Lênin, Marx, Carl Schmitt, Hobbes, Tucídides, Hegel e Aristóteles.

Do estreito contato com Ritter, Lübbe assimilou três coisas fundamentais: o conceito-chave de "compensação", a recusa em dissociar sociologia, filosofia sistemática e história da filosofia, e, por fim, uma concepção de filosofia "enquanto teoria da sociedade moderna" (Lübbe, 2010, p. 103). Pode-se afirmar que em nenhuma das tendências dominantes do pensamento alemão do século 20 a ênfase na historicidade se harmonizou de forma tão produtiva com a reflexão meta-histórica, de um lado, e com a práxis historiográfica, de outro. Para isso contribuiu ainda, nos casos de Marquard e Lübbe, a participação em dois fóruns a partir dos quais emergiram, talvez se possa dizer, alguns

\footnotetext{
${ }^{6}$ No seu ensaio "Carl Schmitt em recepção liberal”, Lübbe lembra que em fins dos anos 1950 a crítica schmittiana do liberalismo era lida no collegium philosophicum em chave liberal, a contrapelo de si mesma. Predominava entre os alunos de Ritter o que se poderia chamar de anti-antiliberalismo, mas não a ponto de se estabelecerem tabus intelectuais. $\mathrm{O}$ confronto com a obra do grande jurista (que, a convite, chegou a estar presente em alguns encontros) era feito de forma eclética e se guiava pela "regra paulina de tudo colocar à prova e ficar com o que é bom" (Lübbe, 1989, p. 311).
} 
dos principais temas que perseguimos ainda hoje em nossas agendas de investigação. Referimo-nos às reuniões do grupo Poética e Hermenêutica, criado em 1963 por Blumenberg e Hans Robert Jauss (Spoerhase, 2010); e ao grupo de trabalho Teoria da História, patrocinado pela Fundação WernerReimers a partir de 1970. Participando ativamente deste último, Lübbe trabalha em conjunto com Reinhardt Koselleck, Niklas Luhmann, Karlheinz Stierle, Jürgen Kocka e Thomas Nipperdey. Seu importante livro Conceito de história e interesse histórico (Lübbe, 1977) é fruto deste convívio.

Faz-se necessário, neste ponto, dar um passo atrás e dedicar algumas palavras aos primeiros trabalhos histórico-filosóficos de Lübbe. Entre as décadas de 1950 e 1980 o conceito de secularização ocupava um lugar estratégico em diversas teorias sobre a modernidade, abrangendo um espectro de autores que se estendia de Karl Löwith e Eric Voegelin aos representantes da teoria crítica. É bom lembrar: ainda em 1933, Carl Schmitt afirmara que "sem o conceito de uma secularização, não é possível o entendimento dos últimos séculos de nossa história" (Schmitt, 2006, p. 3). O que advém, todavia, se a tese da secularização é posta sob suspeita, para finalmente soçobrar sob o peso das evidências de que a religião não é a anti-modernidade? Três estudos publicados em meados da década de 1960 anteciparam tudo o que havia e há de apressado na ideia de um refluxo do religioso: O problema da religião na sociedade moderna, de Thomas Luckmann; Secularização: história de um conceito político, de Lübbe; e A legitimidade da era moderna, de Hans Blumenberg. ${ }^{7}$

Ao contrário de outras comunidades intelectuais, como se sabe, o problema da religião jamais esteve ausente da agenda do pensamento históricofilosófico alemão, e isso se prolonga século 20 adentro. Se a secularização de fato acontece, então tanto aqueles que viam na modernidade uma queda rumo ao sempre pior, como aqueles que nela viam uma ascensão gradativa em direção ao cada vez melhor, poderiam reclamar alguma concretude para as suas previsões. Forma-se assim uma curiosa aliança entre o que Lübbe (2003, p. 139) chama de "apologetas da modernização" e "defensores do cristianismo".

Há muito, porém, o conceito deixou de ser meramente descritivo. De forma espetacular, Blumenberg demonstrou que quem fala em secularização tende a tornar ilegítima a modernidade. Para quem emprega o conceito, esta

\footnotetext{
$\overline{7}$ No Congresso alemão de Filosofia de 1962, Lübbe e Blumenberg fizeram suas conferências na sessão dedicada ao tema da secularização. Isso nos leva a crer que possa ter havido uma concepção de fundo comum por detrás dos livros que ambos dedicaram à história deste conceito.
} 
assentaria numa espécie de expropriação de instituições e do aparato mental justamente daquele mundo que a modernidade pretendeu ter suplantado. "Secularização", enfim, é uma categoria produtora de ilegitimidade histórica (Blumenberg, 2008).

Mas se não há secularização, então a razão estaria mais próxima daqueles que não veem na história ocidental dos últimos cinco séculos um processo com uma direção definida ou dotado de alguma misteriosa lógica interna (seja de decadência, seja do seu oposto), bem como daqueles que postulam que religião é um universal antropológico (Luckmann, 2014; Mata, 2014). É destas duas perspectivas que Lübbe, a partir da sua história conceitual, se aproxima. Como Blumenberg, ele ressaltou em seu livro de 1965 o caráter essencialmente pragmático-polêmico da noção de secularização. Tais investigações seriam complementadas, mais tarde, por seus trabalhos sobre as ideologias totalitárias do século 20 e a civil religion enquanto transfigurações especificamente modernas do religioso (Habermas, como sabemos, precisou esperar o $11 \mathrm{de}$ setembro de 2001 para admitir que houvesse algo de errado com a crença no declínio inexorável da religião). ${ }^{8}$

Mas as preocupações de Lübbe não se limitaram apenas à prática da história conceitual. Em 1974, num congresso realizado em Moscou, ele apresenta sua concepção da história dos conceitos como uma modalidade de pesquisa histórica que tem por objeto não simplesmente entidades linguísticas, mas “esquemas de ações de diferenciação". Conceituar significa, primariamente, distinguir o que uma coisa é ou não é. Nesse sentido, a história dos conceitos pode ser entendida como a história de tais esquemas de diferenciação. Mas como estas histórias não respondem a uma lógica imanente aos próprios conceitos, ela só pode ser escrita se levarmos em conta o agir humano em seu sentido mais amplo. A história dos conceitos, portanto, não pode deixar de ser "parte da história geral da práxis humana" (Lübbe, 1975, p. 10). Bem familiarizado com a filosofia da linguagem, cedo ele reconheceu que a dimensão pragmática não pode ser simplesmente extirpada dos conceitos

\footnotetext{
${ }^{8}$ Em um de seus mais importantes ensaios a respeito, publicado originalmente em 1986, Lübbe observava que "processos de secularização são processos sociais em que o pertencimento dos indivíduos a instituições religiosas é neutralizado em relação a seus demais laços sociais. Portanto, nesses termos, o conceito de secularização - para além de seu sentido mais antigo e ainda normativo no direito eclesiástico - é um conceito da sociologia da religião. Mas ele não é um conceito da filosofia da religião, e quem descreve processos de secularização, descreve transformações da realidade da vida social. A realidade da vida religiosa não é tematizada aí. Desde o iluminismo, os processos de secularização marcam os pressupostos jurídicos e sociais da religião. Mas estes não devem ser confundidos com processos de dissolução da religião" (Lübbe, 1995, p. 173. Os grifos são meus.).
} 
(Lübbe, 2010, p. 187). Eis porque disputas acadêmicas tendem a ser também, em larga medida, "disputas por palavras" (Lübbe, 1967).

Seu livro de estreia é um livro de história, uma história da filosofia política na Alemanha. Publicado em 1963, este tratado conciso e altamente compreensivo abrange o período que vai da morte de Hegel até a Primeira Guerra Mundial, quando até mesmo autores como Werner Sombart, Max Scheler e Georg Simmel sucumbiam à celebração da guerra e da nação. Trata-se, neste livro, da releitura de um passado não tão distante a partir da perspectiva da segunda democracia alemã, àquele momento celebrando apenas quatorze anos. Lübbe dá especial importância a intelectuais como Friedrich Meinecke e Ernst Troeltsch porque entende que a Alemanha hodierna deveria se mostrar capaz, como os "racional-republicanos" de inícios dos anos 1920, de se reconciliar com as ideias liberal-democráticas (Lübbe, 1963, p.227-234). O que chama a atenção aqui - e que já o afasta de Habermas tanto quanto revela a forte ascendência de Ritter - é a forma como Lübbe se relaciona com Hegel. Nele, Lübbe busca não o espírito universal ou o fervor teleológico, mas a maneira como Hegel articulou a herança da ilustração à realidade política de seu tempo. Seu interesse último se volta, por assim dizer, para a astúcia da ilustração. Outro aspecto decisivo em sua leitura da filosofia do direito de Hegel é que esta, a seu ver, não permite a identificação de um sujeito privilegiado do processo histórico. Hegeliana é, enfim, a inspiração para promover a historicização dos conceitos e da própria filosofia (Lübbe, 1962a, p.7-17). A distância em relação a Habermas se manifesta também em sua forma de se apropriar do pensamento de Max Weber. O Weber de Habermas é o formulador da ideia de um inexorável desencantamento do mundo, enquanto o de Lübbe é o defensor de uma distinção fundamental entre juízos de valor e juízos de realidade, o Weber inimigo de toda instrumentalização política do conhecimento.

\section{4}

Na contramão de uma legião de vozes, Lübbe não vê no historicismo uma relíquia do século 19. Ele prefere falar num historicismo cultural especificamente moderno e constata a "progressiva tendência à autohistoricização de nossa civilização" (Lübbe, 1996, p.146 e 149). Se entendermos o conceito de historicismo em uma de suas acepções originárias, a de um "excesso" de história, o diagnóstico de Lübbe é que as características próprias das sociedades técnico-industriais nos condenam ao historicismo. ${ }^{9}$

\footnotetext{
9 Só recentemente a resiliência do historicismo passou a merecer maior atenção no campo da teoria da história. Cf. Mata (2008), Ankersmit (2010), Scholtz (2011) e Bevir (2012).
} 
Com isso passamos ao nosso próximo tema, a reflexão sobre o tempo presente desenvolvida por Lübbe numa longa série de publicações. Há aqui uma clara inspiração nos trabalhos pioneiros de Ernst Benz e Reinhart Koselleck sobre a aceleração do tempo, fenômeno que ele transformou - bem antes que sociólogos o fizessem - num extenso programa de pesquisa, e cujas implicações se mostram de largo alcance não apenas para a ciência histórica, mas também para as ciências sociais e a filosofia. Uma breve consideração a respeito das posições de três outros autores nos ajudará a situar melhor a importância do trabalho de Lübbe neste campo.

Mantendo-se nas sendas da teoria crítica, Hartmut Rosa centra sua análise no que ele chama de "patologias sociais" advindas da intensificação dos ritmos sociais. A perda de sincronia entre as esferas econômica e política constituiria a mais ameaçadora das "tendências desintegrativas de nossa sociedade" (Rosa, 2013, p. 259-260). Sem dúvida há algo de paradoxal em seu plaidoyer a favor dos processos de desaceleração social. Pois ser progressista, hoje, implicaria em assumir uma postura conservadora, ou no mínimo ambígua, em relação ao tempo. Não há dúvida: as antigas sinonímias existentes entre "esquerda" e mudança, entre "direita" e conservadorismo, perderam muito de sua antiga força. Basta observar como, desde os anos 1960, se alterou profundamente a semântica do conceito de "reforma". Em países como o Brasil e a França, ser de esquerda significa atualmente opor-se resolutamente às "reformas".

A partir da perspectiva da teoria dos sistemas, Armin Nassehi chega a conclusões bem diferentes das de Rosa. Para ele o que é característico da experiência do tempo nas sociedades modernas, complexas, é a coexistência de distintos regimes temporais. A perspectiva "engajada" de Rosa, seu "cronopolitismo", enfim, o impediriam de ver com clareza aquilo que, em nossa época, impõe severos limites ao político. Nassehi aposta ainda na retomada da contribuição de Arnold Gehlen: suas "previsões de início dos anos 1960, inicialmente sucedidas por uma fase otimista, [...] são confirmadas e radicalizadas por uma semântica temporal em expansão desde fins dos anos 1980" (Nassehi, 2008, p. 333).

O cronopolitismo de Rosa coloca-o nas proximidades da "dromologia" de Paul Virilio (2007), sobretudo naquilo que ela tem de mais frágil: sua unilateralidade. Caso prevalecesse apenas a "lei da velocidade", já não seríamos capazes de nos orientar eficazmente no mundo da vida, o que evidentemente não é o caso. Alheia a toda forma de hiperbolização, a abordagem de Lübbe (2014) oferece-nos uma alternativa interessante ao trabalhar com o conceito de "dinâmica civilizacional" moderna. Tal como Lübbe o concebe, este termo contempla e pressupõe ambas as possibilidades - a aceleração e o seu oposto. 
Avesso à aversão pelo empírico e ancorado, como vimos, na melhor tradição fenomenológica, Lübbe reuniu evidências fortes do excesso de história que marca nossa época: expansão sem precedentes da categoria profissional dos historiadores (inclusive daqueles que, no interior de cada disciplina científica, promovem a sua auto-historicização); ${ }^{10}$ interesse crescente do grande público por obras de história; crescimento exponencial da rede de museus e das políticas de preservação etc. ${ }^{11}$ Nenhuma civilização anterior à nossa se interessou tanto pelo próprio passado.

Por que, pergunta-se Lübbe (1996, p. 149-150) "na nossa modernidade presente o passado progressivamente ganha em evidência?". Para explicar isso, ele propôs o conceito de "encolhimento do presente". Pode-se resumi-lo em poucas palavras. Trata-se de uma "diminuição da extensão dos espaços de tempo para os quais nós podemos contar com uma certa constância de nossas condições de vida" (Lübbe, 1996, p. 150). É certo que desde sempre e por toda a parte houve mudanças qualitativas, evolução civilizacional, numa palavra: história. Mas com o advento das revoluções Francesa e Industrial, de um mundo no qual tudo que é sólido desmancha no ar, o fenômeno que Ernst Bloch pioneiramente chamou de "não-contemporaneidade do contemporâneo" - ou seja, a sobreposição de (e mesmo o conflito entre) diferentes ritmos temporais no interior de uma mesma sociedade - torna-se uma experiência recorrente para a maioria das pessoas. Uma das muitas evidências do encolhimento do presente, Lübbe a retira de um estudo de Hans Robert Jauss em que se mostra que entre 1850 e 1900 surgiram sete novas designações de estilos de época, ao passo que entre 1960 e 1970 surgiram quatorze. Nota bene: o dobro de estilos para a metade da unidade de tempo. Aceleração temporal.

Coloca-se aqui, ainda, o problema da função da consciência histórica num mundo regido pela lógica da perpétua autossuperação. Graças a Koselleck (2006) sabemos que a função atribuída à pesquisa histórica na Europa pré-moderna estava subsumida na fórmula historia magistra vitae. Em condições de acelerada dinâmica civilizacional esta função tem sua importância diminuída. Em consonância com a fenomenologia das histórias de

\footnotetext{
${ }^{10}$ Vale igualmente para a história da historiografia, disciplina que em inícios da década de 1960 era praticada, dizia Lübbe, apenas no interior de círculos "esotéricos" (Lübbe, 1962b, p. 205). O fenômeno generalizou-se a tal ponto nos últimos anos que "foi como historiadores da matemática que matemáticos famosos mantiveram-se conhecidos em sua velhice" (Lübbe, 2016, p. 289).

${ }^{11}$ No Brasil, foi justamente no momento em que o modernismo se torna um projeto artístico consequente e a modernização econômica uma política de estado, que se coloca a necessidade de institucionalização da preservação do patrimônio através do Instituto do Patrimônio Histórico e Artístico Nacional (Iphan). Eis aí um caso emblemático da dialética compensatória que se desenvolve entre aceleração civilizacional e historicização de que fala Lübbe (2016).
} 
Schapp (2007), Lübbe entende que a função primordial da consciência histórica é a produção de identidade (Lübbe, 1996, p. 151-152). ${ }^{12}$ Nesse sentido, o encolhimento do presente gera uma dificuldade: tal processo implica num estranhamento crescente de indivíduos e grupos face àqueles passados com os quais estavam até então familiarizados. Estes são substituídos por novos passados, ou antes, a cada instante novas camadas de passado são sobrepostas às mais antigas. Com isso se neutralizaria o potencial de produção/manutenção de identidade subjacente a toda forma de presentificação do passado? Lübbe não acredita nisso. Uma consciência histórica cientificamente disciplinada sempre é chamada a nos reapresentar aqueles passados, tornando-os novamente compreensíveis e adaptados a nossas demandas atuais por identidade. Com o encolhimento do presente, tanto maior a necessidade de consciência histórica a fim de compensar a perda cultural de familiaridade com o passado - perda, portanto, de orientação. Lübbe conclui que "a cultura histórica é uma cultura especificamente moderna, e cuja necessidade cresce par e passo com a dinâmica da civilização moderna" (Lübbe, 1996, p. 152).

De tal modo que a fórmula de Habermas deveria ser invertida: o antihistoricismo é que é a antimodernidade. Estamos condenados ao historicismo justamente porque as sociedades contemporâneas são estruturalmente dinâmicas. Quanto mais rápido as mudanças se produzem, tanto maior a quantidade daquilo que, no espaço de uma vida, experimentamos como "passado". A modernidade assenta numa pluralização e dinâmica crescentes, e nós a vivenciamos em sua plenitude. Não se trata de um projeto inacabado. Como observa Jens Hacke (2006a), Lübbe mantém uma atitude de profunda desconfiança ante todo aquele que se arroga a capacidade de vislumbrar como este suposto "projeto inacabado" haverá de chegar a seu termo. Extraindo todas as consequências da crítica de Popper às filosofias da história, Lübbe afirma que "o futuro da evolução cultural está aberto, porém a política que esteja orientada por uma ideologia que trata o futuro como algo fixo por meio de uma sucessão de épocas determinada por leis, inevitavelmente transforma uma sociedade aberta em uma sociedade fechada" (Lübbe, 2009, p. 169).

Percebe-se aqui a centralidade da noção de compensação, e cujo aroma hegeliano é evidente. Nenhuma tendência se manifesta sem que surja uma outra força, oposta, que em certa medida a possa contrabalançar (Marquard, 2013). Com o advento da consciência histórica, o homem já não pode viver sem fazer história. Mas, ao mesmo tempo, ele é incapaz de viver e se orientar minimamente quando tudo à sua volta se transforma cada vez mais velozmente.

\footnotetext{
${ }^{12}$ Sobre sua estreita ligação com Schapp, ver Lübbe (2004).
} 
Ele deseja a mudança e, simultaneamente, precisa da não-mudança. A razão para isso é que há em nós uma demanda antropológica básica por permanência, pela manutenção de pontos de referência relativamente fixos, por meio dos quais orientamos nossa ação no mundo (Marquard, 2012). Os que passaram pela experiência da hiperinflação brasileira na década de 1980 (se poderia caracterizá-la como uma historicização desenfreada do referencial "valor" dos meios monetários) sabem que a contingência e a historicidade são capazes de afligir tanto quanto a fixidez. Nas chamadas jornadas de junho de 2013 tal dilema se manifestou no conflito, violento às vezes, entre aqueles para os quais os partidos (esta forma tradicional - com isso se quer dizer: histórica - de organizar racionalmente a ação política) nada mais têm a nos dizer, que ela teria sido ultrapassada pelos acontecimentos; e aqueles que, sadiamente, compreendem que esta instituição secular, o partido político, deve ser preservada pela simples razão que as alternativas a ele nos parecem irrealistas, senão perigosas. Percebe-se com clareza a lógica da compensação produzida pela aceleração civilizacional. O mais simples common sense indica que a atitude "conservadora", isto é, a preservação das tradicionais formas de institucionalização da ação política, não obstante vivam hoje uma crise sem precedentes, implica em menos riscos para a sociedade do que o grande salto no escuro do espontaneísmo e do anti-institucionalismo.

Estas considerações a respeito da história brasileira recente dão ensejo a que evoquemos um outro conceito cunhado por Lübbe na década de 1990, o de "adensamento de redes" (Netzverdichtung). Creio que a partir desta noção se pode lançar luz sobre um (e apenas um) aspecto dos eventos de 2013.

É notório que para a deflagração daquela impressionante onda de protestos contribuiu, ainda que na condição de mero estopim, o problema do transporte coletivo nas nossas metrópoles. Gostaria de defender a tese de que para se compreender o sucesso da mobilização do Movimento pelo Passe Livre, ou pelo menos a simpatia generalizada que suscitou, contribuiu menos a questão estritamente econômica (o aumento da tarifa) do que o apagão da mobilidade nas grandes cidades brasileiras. Numa palavra: em seu nascedouro a revolta foi também, em boa medida, uma revolta contra a longa duração.

Convém explicar; e aqui entra o conceito de adensamento de redes. Ele designa a crescente articulação entre formas de comunicação e formas de deslocamento nas sociedades contemporâneas. De um lado, temos redes por meio das quais signos são intercambiados, de outro redes por meio das quais os produtores destes signos se deslocam. Lübbe mostra que existe uma evidente complementaridade entre meios de comunicação e meios de transporte. Os processos de adensamento destas duas formas de rede se 
deu quase que exponencialmente após a revolução industrial. Basta dizer que quando se iniciou a instalação da rede de telefonia na Alemanha, havia em média uma linha telefônica por grupo de 100 habitantes. O número de linhas quintuplicou até 1930 , tendo se multiplicado por doze nas três décadas seguintes. "Todos", constata Lübbe (1996, p.29), "indivíduos e instituições, estão direta e inescapavelmente ligados com todos". O mesmo efeito é obtido por meio da expansão da rede de rodovias e ferrovias.

De tudo isso Lübbe (1996, p. 29) extrai duas consequências importantes. A primeira: "mais rapidamente ainda que o número daqueles que nelas participam, crescem as desvantagens de não se estar conectado a uma rede". A segunda, e mais importante para o nosso caso: o ininterrupto desenvolvimento da técnica faz com que os processos de comunicação se tornem cada vez menos dependentes das redes de transporte. Se nas sociedades pré-modernas a agilidade da troca de informações estava em estrita dependência da quantidade e qualidade dos meios e vias de transporte, na nossa civilização deu-se uma virtual dissociação entre tempo e espaço nos processos comunicativos. A carta é hoje um sobrevivente - sabe-se lá até quando - de uma época em que o tempo dispendido para receber uma mensagem estava intimamente relacionado ao fator espacial. Seria um truísmo dizer que a situação se alterou radicalmente ao longo das últimas décadas. De fato, Lübbe afirma que o adensamento de redes produz "efeitos de descentralização" (evidentes no caso do pesquisador que não precisa mais se submeter a uma longa e dispendiosa viagem à Europa para estudar seus autores preferidos, nem se submeter à estressante rotina dos grandes centros). Ele constatava já em 1996 - portanto bem antes da massificação dos telefones celulares e das "redes sociais" - que esta autonomização das redes de comunicação em face das redes de locomoção produziria consequências revolucionárias do ponto de vista cultural (Lübbe, 1996, p. 30).

A dinâmica civilizacional moderna leva, assim, a um inexorável processo de adensamento de redes, mas também - e isso Lübbe não chegou a perceber a uma assimetria crescente entre a velocidade com que as mensagens se deslocam e a velocidade com que os emissores de mensagens de deslocam. A utopia da mobilidade total esbarra em limitações espaciais e na evidente sobrecarga do sistema de tráfego urbano. Dá-se então o curioso e irritante paradoxo de que graças ao avanço da técnica eu posso me informar, por meios diversos e em tempo real, sobre um evento que acontece em minha cidade, mas caso queira me deslocar até lá a fim de acompanhá-lo pessoalmente, inevitavelmente terei de despender um quantum desproporcional do meu próprio tempo real. Esta irritação que se abate sobre nós em tais momentos 
provavelmente tem suas raízes nas camadas mais profundas da psique. Lübbe (1997, p. 64) chega mesmo a considerar o desejo de mobilidade (Mobilitätslust) como uma constante antropológica. ${ }^{13}$ As consequências extremas da constante frustração desta constante, isto é, da inibição da pulsão humana por mobilidade, são o tema do conhecido filme estrelado por Michel Douglas, Um dia de fúria.

Um dos paradoxos identificados por Lübbe em contextos marcados pela aceleração civilizacional é que com a gradativa melhoria do padrão de vida, aumenta, na mesma medida, nossa sensibilidade e nossa intolerância para com os custos da modernização. Que a mobilidade tornou-se um tema político nos dias de hoje, mostra-o o acirrado debate que se dá na Alemanha todas as vezes em que se fala em estabelecer um limite de velocidade nas autoestradas daquele país.

Nesse sentido, e tomando por base a fenomenologia da dinâmica evolucionária das sociedades contemporâneas desenvolvida por Lübbe, seria possível dizer que uma das causas por detrás dos protestos de 2013, ao menos naquilo que parece tê-los deflagrado, foi a frustração diante do não cumprimento desta promessa com que nos acenava a modernidade: a mobilidade irrestrita. O que esteve em jogo ali, de início, não foi apenas uma revolta contra a escandalosa distância entre o custo do transporte e o que ele efetivamente proporciona aos cidadãos (em condições de aceleração civilizacional, haveria de ser: um mínimo de conforto e rapidez). Trata-se, também e em última análise, de uma revolta contra o abismo temporal que se instalou, de um lado, entre a extraordinária agilidade das mídias e das redes sociais e, de outro, a longa duração a que está condenado o mais simples ir-evir em nossas grandes cidades.

Em suma, uma revolta generalizada em que a questão da mobilidade ocupou um lugar tão importante (inclusive na principal modalidade de protesto e de pressão empregados: o bloqueio do tráfego), é em larga medida uma revolta contra o tempo, ou antes: contra o paradoxo de estarmos submetidos à longa duração justamente em sociedades sob a égide da aceleração. Uma revolta, enfim, que põe a nu a situação aporética da experiência do tempo nas grandes metrópoles contemporâneas.

Não é o caso de avançar aqui na exposição de todos os conceitos elaborados por Lübbe em sua esclarecedora fenomenologia do tempo presente. Acreditamos ter cumprido a tarefa de ao menos esboçar uma introdução ao seu pensamento. Mas já que demos o devido espaço à opinião de seus críticos,

\footnotetext{
${ }^{13}$ Em seu ensaio Der mobile Mensch, Gehlen (2004, p. 452) escreve que "nunca esteve na natureza do ser humano ficar colado a um lugar".
} 
parece justo evocar também a de um de seus mais próximos amigos, aquele que, a seu lado, contribuiu para fazer da "escola" de Joachim Ritter um dos mais importantes acontecimentos intelectuais da segunda metade do século 20.

Ao longo de sua vida e da trajetória do seu pensamento, ele passou por todas as posições filosóficas pelas quais os mais sensíveis de seus contemporâneos passaram, só que o fez muito mais rápido e muito antes. Quando Habermas ainda pensava sob o feitiço de Heidegger, Lübbe já estava com Marx. Quando, depois da Segunda Guerra Mundial, a Escola de Frankfurt redescobriu que era Escola de Frankfurt, Lübbe já a havia deixado para trás. Quando esta se converteu ao neomarxismo, Lübbe já estava com a socialdemocracia reformista. Quando este partido rico de tradições ${ }^{14}$ passou aos sonhos utópicos e à nostalgia da revolução, Lübbe recordou-lhe suas tradições liberais por meio de uma filosofia ilustrada sem perda de senso de realidade. A ilustração deixou, assim, os intelectuais de vanguarda para trás. A filosofia de Hermann Lübbe se converteu contudo em uma das formas mais modestas e mais vivamente inteligentes da ilustração filosófica de que dispomos hoje (Marquard, 2000, p. 123).

O mais influente diário alemão resumiria as palavras acima num misto de rigor eidético e fino senso de humor: Vom Philosophen Hermann Lübbe hiess es einst, wer zusammen mit ihm in einen Flieger steige, komme trotzdem später an (Frankfurter Allgemeine Zeitung, 12 dez. 2005). ${ }^{15}$

Em seu livro mais conhecido, Wilhelm Schapp (2007, p. 186) evoca uma frase de Husserl quando este lecionava em Göttingen, reunindo em torno de si um pequeno círculo de alunos. "Deveríamos ter ainda um historiador", lamentou na ocasião o fundador do método fenomenológico. Lübbe se pergunta se a filosofia das histórias de Schapp teria sido uma tentativa de preencher tal lacuna (Lübbe, 2004, p. 40). Estamos inclinados a acreditar que a resposta a esta questão só poderia ser negativa. Schapp era, quando muito, um metahistoriador. Por muito que possa adquirir certa sensibilidade fenomenológica, é ainda preciso ter em mente que a história "é e continua sendo uma "ciência empírica" (Koselleck, 2003, p.30). Como quer que seja, Hermann Lübbe talvez nos tenha dado, ao recuperar este episódio, a senha para a compreensão de seu próprio legado intelectual.

\footnotetext{
${ }^{14}$ Marquard se refere ao Partido Social-Democrata Alemão (SPD).

15 "Já se disse do filósofo Hermann Lübbe que se alguém entrasse com ele num mesmo avião, ainda assim chegaria mais tarde".
} 


\section{Referências}

ANKERSMIT, Frank. The necessity of historicism. Journal of the Philosophy of History, v. 4, n. 2, p. 226-240, $2010<10.1163 / 187226310 X 509547>$.

APEL, Karl-Otto. Estudios éticos. México: Fontamara, 1999.

BEVIR, Mark. In defense of historicism. Journal of the Philosophy of History, v. 6, n. 1, p. 111-114, $2012<10.1163 / 187226312 X 625627>$.

BLUMENBERG, Hans. La legitimación de la edad moderna. Valencia: Pre-Textos, 2008.

GEHLEN, Arnold. Der mobile Mensch. In: Arnold Gehlen. Gesamtausgabe. Band VI. Frankfurt am Main: Klostermann, 2004.

HABERMAS, Jürgen. The new conservatism. Cambridge: MIT Press, 1989.

HABERMAS, Jürgen. Die Grenzen des Neuhistorismus. In: Jürgen Habermas. Die nachholende Revolution. Frankfurt am Main: Suhrkamp, 1990.

HACKE, Jens. Der Hüter des common sense. Berliner Zeitung, 30 dez. 2006a.

HACKE, Jens. Philosophie der Bürgerlichkeit. Göttingen: Vandenhoeck \& Ruprecht, 2006 b.

HUYSSEN, Andreas. Después de la gran división. Buenos Aires: Adriana Hidalgo, 2006.

KOHLER, Georg; KLEGER, Heinz (orgs.). Diskurs und Dezision: politische Vernunft in der wissenschaftliche-technischen Zivilisation. Hermann Lübbe in der Diskussion. Wien: Passagen, 1990.

KOSELLECK, Reinhart. Zeitschichten. Studien zur Historik. Frankfurt am Main: Suhrkamp, 2003.

KOSELLECK, Reinhart. Futuro passado: contribuição à semântica dos tempos históricos. Rio de Janeiro: Contraponto, 2006.

LORIG, Wolfgang H. Neokonservatives Denken in der Bundesrepublik Deutschland und in den Vereinigten Staaten von Amerika. Opladen: Leske \& Budrich, 1988.

LÜBBE, Hermann. Das Ende des phänomenologischen Platonismus. Tijdschrift voor Philosophie, v. 16, n. 4, p.637-666, 1954.

LÜBBE, Hermann. Einleitung. In: Hermann Lübbe. Die hegelsche Rechte. Stuttgart: Friedrich Fromann, 1962a.

LÜBBE, Hermann. Philosophiegeschichte als Philosophie. $\mathrm{Zu}$ Kants Philosophiegeschichtsphilosophie. In: Klaus Oehler; Richard Schaeffler (orgs.) Einsichten. Gerhard Krüger zum 60. Geburtstag. Frankfurt am Main: Klostermann, 1962b.

LÜBBE, Hermann. Politische Philosophie in Deutschland: Studien zu ihren Geschichte. Basel: Schwabe \& Co., 1963.

LÜBBE, Hermann. Der Streit um Worte. Sprache und Politik. In: Hessische Blätter für Volksbildung, v. 2-3, p. 107-125, 1967. 
LÜBBE, Hermann. Begriffsgeschichte als dialektischer Prozess. Archiv für Begriffsgeschichte, v. 19, p. 8-15, 1975.

LÜBBE, Hermann. Geschichtsbegriff und Geschichtsinteresse. Basel: Schwabe \& Co., 1977.

LÜBBE, Hermann. Laudatio. In: Karlfried Gründer et al. Gedenkschrift Joachim Ritter. Münster: Aschendorff, 1978.

LÜBBE, Hermann. Zwischen Trend und Tradition: Überfordert uns die Gegenwart? Zürich: Interfrom, 1981.

LÜBBE, Hermann. Die Aufdringlichkeit der Geschichte: Herausforderungen der Moderne vom Historismus bis zum Nationalsozialismus. Graz: Styria, 1989.

LÜBBE, Hermann. Nach der Aufklärung. Über den kulturellen Bedeutsamkeitsverlust wissenschaftlicher Weltbilder. In: Jürgen Audretsch (org.). Die andere Hälfte der Wahrheit: Naturwissenschaft, Philosophie, Religion. München: Beck'sche Reihe, 1992.

LÜBBE, Hermann. Fortschritt durch Wissenschaft. Die Universitäten im 19. Jahrhundert. In: Wolfgang Hardtwig; Harma-Hinrich Brandt (orgs.). Deutschlandsweg in die Moderne. München: C. H. Beck, 1993.

LÜBBE, Hermann. La sécularisation ou l'affaiblissement social des institutions religieuses. Revue de Métaphysique et de Morale, v. 100, n. 2, p. 165-183, 1995.

LÜBBE, Hermann. Zeit-Erfahrungen: Sieben Begriffe zur Beschreibung modernen Zivilisationsdynamik. Mainz: Franz Steiner, 1996.

LÜBBE, Hermann. Mobilität - vorerst unaufhaltsam. In: Hermann Lübbe. Modernisierung und Folgelasten. Berlin: Springer, 1997.

LÜBBE, Hermann. Säkularisierung: Geschichte eines ideenpolitischen Begriffs. Freiburg: Karl Alber, 2003.

LÜBBE, Hermann. Lebensweltgeschichten: Philosophische Erinnerungen an Wilhelm Schapp. In: Karl-Heinz Lembeck (org.). Geschichte und Geschichten: Studien zur Geschichtenphänomenologie Wilhelm Schapps. Würzburg: Könighausen \& Neumann, 2004.

LÜBBE, Hermann. The contraction of the present. In: Hartmut Rosa; William Scheuerman (orgs.). High-speed society: social acceleration, power, and modernity. Pennsylvania State: University Press, 2009.

LÜBBE, Hermann. Hermann Lübbe im Gespräch. München: Wilhelm Fink, 2010.

LÜBBE, Hermann. Zivilisationsdynamik: Ernüchterter Fortschritt politisch und kulturell. Basel: Schwabe, 2014.

LÜBBE, Hermann. Esquecimento e historicização da memória. Estudos Históricos, v. 29, n. 57, p. 283-298, $2016<10.1590 /$ S0103-21862016000100015>.

LUCKMANN, Thomas. A religião invisível. São Paulo: Loyola, 2014.

MARQUARD, Odo. Aufklärung mit Wirklichkeitssinn. Zum 70. Geburtstag von Hermann Lübbe. In: Odo Marquard. Philosophie des Stattdessen. Stuttgart: Reclam, 2000. 
MARQUARD, Odo. Breve antropología del tiempo. In: Odo Marquard. Individuo y división de poderes. Madrid: Trotta, 2012.

MARQUARD, Odo. Homo compensator. Sobre a carreira antropológica de um conceito metafísico. Problemata-Revista Internacional de Filosofia, v. 4, n. 2, p. 361-379, 2013 [Zur anthropologischen Karriere eines metaphysischen Begriffs. In: Odo Marquard. Philosophie des Stattdessen. Stuttgart: Reclam, p. 11-29].

MATA, Sergio da. Elogio do historicismo. In: Flávia Varella; Helena Mollo; Sérgio Mata; Valdei Araoujo (orgs.). A dinâmica do historicismo: revisitando a historiografia moderna. Belo Horizonte: Argumentum, 2008.

MATA, Sergio da. O escândalo da religião à luz da protosociologia de Thomas Luckmann. Saeculum-Revista de História, n. 30, p. 191-204, 2014.

MEHRING, Reinhard. Geschichtspragmatik. Eine Rekonstruktion der Geschichtsphilosophie Hermann Lübbes. In: Hanns-Gregor Nissing (org.). Hermann Lübbe: Pragmatische Vernunft nach der Aufklärung. Darmstadt: WBG, 2009.

NASSEHI, Armin. Die Zeit der Gesellschaft: Auf dem Weg zu einer soziologischen Theorie der Zeit. Wiesbaden: VS Verlag für Sozialwissenschaften, 2008.

ROSA, Hartmut. Social acceleration: a new theory of modernity. New York: Columbia University Press, 2013.

SCHAPP, Wilhelm. Envolvido em histórias. Porto Alegre: Sérgio Antonio Fabris, 2007.

SCHELSKY, Helmut. Die skeptische Generation: Eine Soziologie der deutschen Jugend. Düsseldorf: Eugen Diederichs, 1957.

SCHMITT, Carl. Teologia política. Belo Horizonte: Del Rey, 2006.

SCHOLTZ, Gunter. O problema do historicismo e as ciências do espírito no século XX. História da Historiografia, n. 6, p. 42-63, $2011<10.15848 /$ hh.v0i6.239>.

SCHWEDA, Mark. Joachim Ritter und die Ritter-Schule. Hamburg: Junius, 2015.

SPAEMANN, Robert. Schritte über uns hinaus: Gesammelte Reden und Aufsätze I. Stuttgart: Klett-Cotta, 2010.

SPOERHASE, Carlos. Rezeption und Resonanz: Zur Faszinationsgeschichte der Forschungsgruppe "Poetik und Hermeneutik". Internationales Archiv für Sozialgeschichte der deutschen Literatur, v. 35, n. 1, p. 122-142, 2010.

TUGENDHAT, Ernst. Lições sobre ética. Petrópolis: Vozes, 1997.

VIRILIO, Paul. Speed and politics. Los Angeles: Semiotexte, 2007.

Recebido em: 11 maio 2017

Aprovado em: 26 set. 2017

Autor correspondente:

Sérgio da Mata

Departamento de História da Universidade Federal de Ouro Preto

ICHS/Ufop

Rua do Seminário s/n,

35420-000 Mariana, MG, Brasil 